\title{
How Are Cows Cooled on Dairy Farms in Florida?'
}

\author{
Bethany Dado-Senn, Geoffrey E. Dahl, and Jimena Laporta²
}

\section{Heat Stress in the Dairy Industry}

While hot and humid conditions cause grief for dairy producers, additional impacts of heat and humidity on the dairy cow are sometimes overlooked. Dairy cows experience heat stress when the environmental temperaturehumidity index (THI) passes a threshold of 68-72. On average, Florida dairy farms experience this level of heat stress for about 267 days, or $73 \%$ of the year (Ferreira et al. 2016). When exposed to these conditions, a lactating dairy cow will experience reduced fertility, increased risk of metabolic disorders, and lower milk production by about $0.5-1 \mathrm{lb}$ milk/cow/day for every unit of THI above 68. These losses in lactating cow productivity cost the US dairy industry more than $\$ 1.5$ billion every year (St-Pierre, Cobanov, and Schnitkey 2003). This is a growing concern to dairy producers, as more frequent and severe fluctuations in temperature, precipitation, and droughts are predicted to occur in the United States.

Even though many farms in the United States have adopted heat abatement systems such as fans and sprinklers to actively cool lactating cows, dry (non-lactating) dairy cows and pre- and post-weaned dairy heifers are often not considered for heat stress abatement. Reasons include lower susceptibility to heat stress, lack of infrastructure, and lack of immediate milk production responses. However, heat stress leads to physiological alterations that have long-term adverse consequences on welfare and productivity in all groups. Research from UF/IFAS demonstrates that cows exposed to heat stress during the dry period will experience a $10 \mathrm{lb} / \mathrm{cow} /$ day drop in production across their entire next lactation, even if cooled during lactation. This loss in yield is partially attributed to impaired mammary gland remodeling that takes place during the dry period (Tao et al. 2011), and it could cost the US dairy industry up to an additional $\$ 800$ million annually (Ferreira et al. 2016). The dry period coincides with the last trimester of gestation, when the dairy calf in utero is growing at the highest rates. Calves exposed to heat stress in utero are lighter and shorter at birth and weaning and less likely to survive to lactation. If entering the lactating herd, they will produce $10 \mathrm{lb} /$ cow/day less milk across their entire first and second lactations (Monteiro et al. 2016). Thus, the impacts of in utero heat stress on the developing fetus appear to be permanent and transgenerational. Dairy calves that experience direct postnatal exposure to high environmental THI will also exhibit reduced average daily gain and impaired immune responses.

\section{Florida Dairy Heat Stress Abatement Survey}

We conducted a survey to determine the heat stress abatement strategies currently utilized by Florida dairy producers for lactating cows, dry cows, and dairy calves. The survey was distributed between December 2017 and December 2018 with a total of 23 dairy producer responses. Participants answered ten questions related to dairy calf and lactating and dry cow management. All answers remained anonymous. This survey was reviewed by the University of

1. This document is AN355, one of a series of the Department of Animal Sciences, UF/IFAS Extension. Original publication date April 2019. Visit the EDIS website at https://edis.ifas.ufl.edu for the currently supported version of this publication.

2. Bethany Dado-Senn, PhD student; Geoffrey E. Dahl, professor; and Jimena Laporta, assistant professor, Department of Animal Sciences; UF/IFAS Extension, Gainesville, FL 32611.

The Institute of Food and Agricultural Sciences (IFAS) is an Equal Opportunity Institution authorized to provide research, educational information and other services only to individuals and institutions that function with non-discrimination with respect to race, creed, color, religion, age, disability, sex, sexual orientation, marital status, national origin, political opinions or affiliations. For more information on obtaining other UF/IFAS Extension publications, contact your county's UF/IFAS Extension office. 
Florida Institutional Review Board under IRB201701871. The objective of this survey was to develop a better understanding of current heat stress abatement strategies used by Florida dairy producers in order to improve monitoring of the implementation of our previous research findings and meet the specific and immediate heat-stress research needs of Florida dairy producers.

\section{Survey Demographics}

Twenty-three survey responses were recorded, representing approximately $25 \%$ of dairy farms in Florida. Of the 23 producers who responded, $56 \%$ were located in north Florida and $44 \%$ were in south Florida. Herd size ranged from 100 to over 2,000 dairy cows per farm. The average herd size was approximately $1,500-2,500$ cows. A total of 31,000-62,000 cows was represented. This accounts for $25-50 \%$ of dairy cows in the state of Florida. Breed composition of these farms was averaged at approximately 90\% Holstein, 7.3\% crossbred (breed crosses unspecified), 2\% Jersey, 0.5\% Brown Swiss, and 0.2\% unspecified breed. Results are reported at the farm level.

\section{Lactating Cow Heat Stress Abatement}

Housing of lactating cows was close to evenly split between freestall (52\%) and pasture (43\%) systems. Here, "pasture" refers to housing rather than nutrition. While pasture systems are popular in this region and considered beneficial for animal welfare, solar radiation and shade accessibility can affect outdoor cow comfort. When offered a choice of pasture or freestall barn in the summer, cows prefer to spend more time on pasture at night when THI is lower, but will stay indoors during the day even if overstocked.

All of the respondents provided heat stress abatement to lactating dairy cows for at least part of the lactation, with $96 \%$ employing abatement for the entirety of the lactation. Types of heat stress abatement varied among farms; many farms utilized a combination of techniques depending on the time of year and stage of lactation of the cows within each pen or barn. The most popular abatement options for lactating cows included fans (87\%) and sprinklers or soakers $(83 \%)$, with fewer farms using cross or tunnel ventilation, shade-only structures, or cooling ponds. Many producers (67\%) set fan and sprinkler systems on temperature and/or humidity controls that were run yearround, allowing for cost savings at lower environmental temperatures. Fans were set to run on average at $66^{\circ} \mathrm{F}$ with a range between $55^{\circ} \mathrm{F}$ and $74^{\circ} \mathrm{F}$, while sprinklers were programmed at $71^{\circ} \mathrm{F}$ on average with a range of $65^{\circ} \mathrm{F}-80^{\circ} \mathrm{F}$.
In nearly complete consensus, producers cited milk production (100\%), reproduction (87\%), cow comfort (100\%), herd health (96\%), milk quality (78\%), and feed efficiency $(83 \%)$ as reasons for including heat stress abatement during lactation.

\section{Dry Cow Heat Stress Abatement}

Dry cow management was consistent among farms: $91 \%$ of farms designated a dry period of 46-60 days, whereas $9 \%$ of farms assigned a dry period exceeding 60 days. Teat sealant and antibiotics were provided at dry-off for at least a portion of cows on $83 \%$ and $87 \%$ of farms, respectively. There were variations in herd average milk produced at dry-off, with most producers targeting 26-50 lb/cow/day $(45 \%)$ or $51-70 \mathrm{lb} / \mathrm{cow} /$ day $(45 \%)$. Pasture systems were more heavily utilized for dry cows (57\%), but freestall or freestall/pasture combinations were also used (26\% and $9 \%$, respectively; Figure 1A).

Eighty-three percent of Florida producers provided some sort of heat stress abatement to dry cows for at least part of the dry period, with $70 \%$ applying for the entire duration of the dry period (Figure 1B). While applying heat stress abatement for a portion of the dry period can partially rescue production, cooling cows for the entire dry period is preferable. It leads to a three- to fivefold increase in milk yield compared to cooling only during the close-up period (3.1 lb/day vs. $8.8-16.5 \mathrm{lb} /$ day) (Tao and Dahl 2013). Due to an increase in pasture-based housing, the technologies utilized for dry period heat stress abatement shifted towards a more even distribution of fans (52\%), soakers (48\%), shade (48\%), and cooling ponds (43\%), with many producers employing a combination of either the first two or the latter two (Figure 1C). Technology as simple as a shade structure to protect from solar radiation is essential to mitigate heat load, lower rectal temperature and respiration rate, and potentially minimize losses in milk production. Adequate area, orientation, and type of shading are important to maximize the abatement potential. However, shade alone is not enough in hot and humid climates. Dry cows on pasture may easily have access to shade, but other technologies such as cooling ponds or pivots can also be implemented to increase cooling. Use of fans and/or sprinklers through feeding barns or freestall facilities is ideal to provide air movement and wetting of the body in addition to shade. An economic analysis from UF/IFAS researchers reported that due to the significant economic losses in milk production if dry cows are heat stressed, providing heat stress abatement in the form of a freestall barn, fans, and soakers would be profitable for $89 \%$ of US dry cows, even if construction of a barn is required (these authors assumed $11 \mathrm{lb} /$ day 
production drop over 340 days, milk price of $\$ 0.44 / \mathrm{kg}$, and facilities cost of $\$ 2,500 /$ stall) (Ferreira et al. 2016). However, every dairy production system is unique, and economic feasibility of abatement technologies should be carefully considered when determining the most effective heat stress abatement program for your operation. Producers who chose not to provide heat stress abatement cited capital cost, operating cost, and inadequate facilities as reasons for not cooling dry cows. Nevertheless, the producers that do provide heat stress abatement highly rank cow comfort, herd health, and milk production as reasons for cooling dry cows. This suggests that past research has been effectively communicated in order to assist producers in making management decisions (Figure 1D).
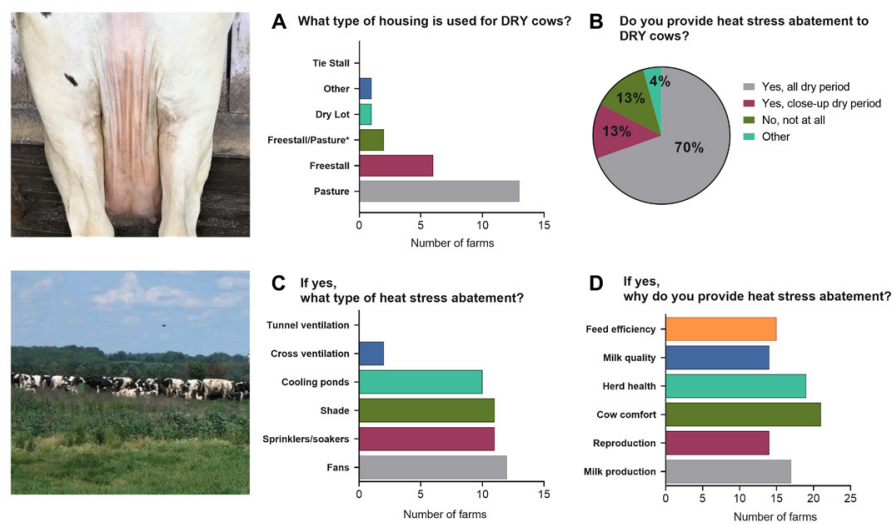

Figure 1. Management strategies for dry dairy cows in Florida. Summary of (A) type of housing, (B) application of heat stress abatement, $(C)$ types of abatement, and (D) reasons for applying abatement. Top image: a dry cow freestall. Bottom image: pasture housing.

Credits: Bethany Dado-Senn, UF/IFAS

\section{Dairy Calf Heat Stress Abatement}

Calf management practices vary across farms. For example, $26 \%$ of farms in this survey did not retain calves and sold them when the animals were between one and seven days old. The reasons for selling were not specified, but one respondent shared in the comments section that they exclusively raised calves from late September to February, implicating heat stress concerns as a cause for calf dispersal. Of the remaining producers who retained calves, 53\% utilized individual hutches, $35 \%$ used group pens, and $12 \%$ incorporated unspecified methods to house calves (Figure 2A). Extensive research has been conducted to determine the heat stress abatement capacities of these housing options. Many studies suggest that individual calf hutches can cause heat stress. Especially in hot and humid climates, calves in individual hutches experience limited heat loss. This occurs because in-hutch air temperatures are often greater than body temperatures, and calves cannot seek out shade beyond the shade of the hutch. Even in moderate
US climates, recent data suggest the average hutch interior reaches a temperature of about $23^{\circ} \mathrm{C}\left(73^{\circ} \mathrm{F}\right)$ and a THI of 68 in the summer months, indicating heat stress (Manriquez et al. 2017). However, certain alterations to hutch environments can alleviate the burden of heat stress. White wooden hutches, shaded hutches, and addition of radiative insulation reduce air and calf body temperatures under summer conditions but provide no direct improvements to production responses such as average daily gain. If producers choose to utilize hutches in calf management, they should consider types of hutches or additions to hutch environment. Group pen systems, utilized by $35 \%$ of producers in this survey, can be better suited for heat stress abatement due to increased area for shade and airflow and the option to add ventilation systems, such as natural ventilation (i.e., curtains and open walls), fans, or positive-pressure tubing. However, the effectiveness of this abatement depends on the environmental temperature, season, bedding, and technologies applied (Hill et al. 2011).

Only $13 \%$ of the Florida dairy producers surveyed provided heat stress abatement beyond shade to their pre-weaned dairy calves; $56 \%$ did not provide abatement and the remaining $31 \%$ sold calves at birth (Figure $2 \mathrm{~B}$ ). We phrased the question to eliminate shade as an abatement option because all calves are exposed to some level of shade in a barn or hutch. This level of heat stress abatement could be partially attributed to the high percentage of producers using individual hutches for housing, where additional abatement strategies beyond shade cannot be easily implemented. Additionally, producers may not prioritize cooling calves or view the practice as economically beneficial. Pre-weaned dairy calves are less susceptible to heat stress due to smaller size and lack of rumination, but they are also less likely to show improvement in production responses such as feed intake and average daily gain under improved microclimates. However, calves under three weeks of age have a thermal neutral zone of $59-78^{\circ} \mathrm{F}$, whereas calves older than three weeks begin to experience heat stress at $68-70^{\circ} \mathrm{F}$, indicating that they can suffer profound effects of heat stress in Florida and the southeastern US (Stull and Reynolds 2008).

Note that only $50 \%$ of producers who employed group housing included additional abatement technologies in their barns. Of those producers that did provide heat stress abatement, all of them utilized basket fan systems (rather than tubes or curtains) that were provided year-round (Figures $2 \mathrm{C}$ and 2D). Further research is needed to determine if this abatement technique is the most effective in providing cooling for pre-weaned dairy calves in Florida climate. 

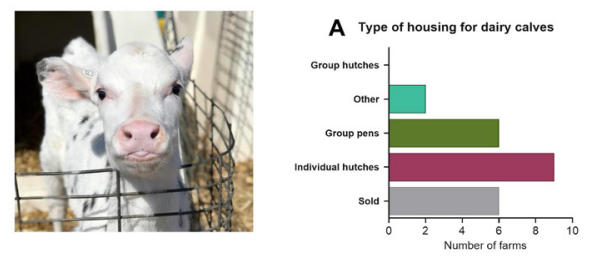

B
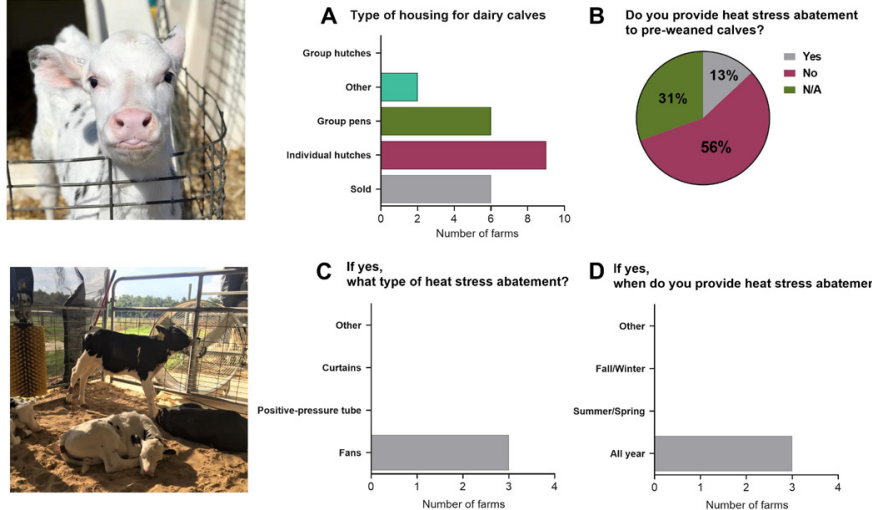

Figure 2. Management strategies for pre-weaned dairy calves in Florida. Summary of (A) types of housing, (B) application of heat stress abatement, (C) types of abatement, and (D) duration of abatement. Top image: dairy calf individual hutch. Bottom image: group housing. Credits: Bethany Dado-Senn, UF/IFAS

\section{Conclusions}

- Dairy producers emphasize providing heat stress abatement to lactating cows, but they have started to implement heat abatement for dry cows.

- Types of abatement differ between groups. Lactating cows are exposed to more fans and sprinklers or soakers, while dry cows either receive fans and soakers in a freestall barn or shade and/or cooling ponds on pasture.

- Only $13 \%$ of producers apply heat stress abatement for dairy calves, all in the form of fans supplied year-round.

- In the future, we will focus our efforts on strategies for pasture-based systems and heat stress abatement technologies for dairy calf facilities and growing heifers.

\section{Acknowledgments}

We would like to thank the Florida dairy producers who completed the survey. We acknowledge Dr. Albert De Vries from UF/IFAS, Rick Dado of Four Hands Holsteins, Brian Chapman from Florida Dairy Farmers, and Travis Senn from Southeast Milk, Inc. for their assistance in the design and/or distribution of the survey.

\section{References}

Ferreira, F. C., R. S. Gennari, G. E. Dahl, and A. De Vries. 2016. "Economic feasibility of cooling dry cows across the United States." J. Dairy Sci. 99: 9931-9941. doi:10.3168/ jds.2016-11566.

Hill, T. M., H. G. Bateman II, J. M. Aldrich, and R. L. Schlotterbeck. 2011. "Comparisons of housing, bedding, and cooling options for dairy calves." J. Dairy Sci. 94: 2138-2146. doi:10.3168/jds.2010-3841.
Monteiro, A. P. A., S. Tao, I. M. T. Thompson, and G. E. Dahl. 2016. "In utero heat stress decreases calf survival and performance through the first lactation." J. Dairy Sci. 99: 8443-8450. doi:10.3168/jds.2016-11072.

Manriquez, D., H. Valenzuela, S. Paudyal, A. Velasquez, and P. J. Pinedo. 2017. "Effect of aluminized reflective hutch covers on calf health and performance." J. Dairy Sci. 101: 1464-1477. doi:10.3168/jds.2017-13045.

Stull, C. and J. Reynolds. 2008. "Calf welfare." Vet. Clin. Food Anim. 24: 191-203. doi:10.1016/j.cvfa.2007.12.001.

St-Pierre, N. R., B. Cobanov, and G. Schnitkey. 2003. "Economic losses from heat stress by US livestock industries." J. Dairy Sci. 86: E52-E77.

Tao, S., J. W. Bubolz, B. C. do Amaral, I. M. Thompson, M. J. Hayen, S. E. Johnson, and G. E. Dahl. 2011. "Effect of heat stress during the dry period on mammary gland development." J. Dairy Sci. 94: 5976-5986. doi:10.3168/ jds.2011-4329.

Tao, S. and G. E. Dahl. 2013. "Invited review: Heat stress effects during late gestation on dry cows and their calves." J. Dairy Sci. 96: 4079-4093. doi:10.3168/jds.2012-6278. 